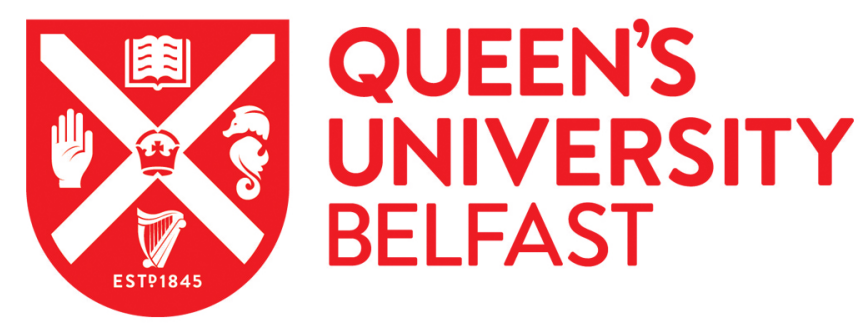

\title{
Collision risk modelling for tidal energy devices: A flexible simulation- based approach
}

Horne, N., Culloch, R., Schmitt, P., Lieber, L., Wilson, B., Dale, A., Houghton, J., \& Kregting, L. (2021). Collision risk modelling for tidal energy devices: A flexible simulation-based approach. Journal of Environmental Management, 278(1), [111484]. https://doi.org/10.1016/j.jenvman.2020.111484

Published in:

Journal of Environmental Management

Document Version:

Peer reviewed version

Queen's University Belfast - Research Portal:

Link to publication record in Queen's University Belfast Research Portal

\section{Publisher rights}

Copyright 2020 Elsevier.

This manuscript is distributed under a Creative Commons Attribution-NonCommercial-NoDerivs License

(https://creativecommons.org/licenses/by-nc-nd/4.0/), which permits distribution and reproduction for non-commercial purposes, provided the author and source are cited.

\section{General rights}

Copyright for the publications made accessible via the Queen's University Belfast Research Portal is retained by the author(s) and / or other copyright owners and it is a condition of accessing these publications that users recognise and abide by the legal requirements associated with these rights.

Take down policy

The Research Portal is Queen's institutional repository that provides access to Queen's research output. Every effort has been made to ensure that content in the Research Portal does not infringe any person's rights, or applicable UK laws. If you discover content in the Research Portal that you believe breaches copyright or violates any law, please contact openaccess@qub.ac.uk. 


\section{Collision risk modelling for tidal energy devices:}

\section{A flexible simulation-based approach}

3 Nicholas Horne ${ }^{1 *}$, Ross M. Culloch², Pál Schmitt ${ }^{3}$, Lilian Lieber ${ }^{3}$, Ben Wilson ${ }^{4}$, Andrew C.

$4 \quad$ Dale $^{4}$, Jonathan D.R. Houghton ${ }^{5}$ \& Louise T. Kregting ${ }^{1}$

5 1. School of Natural and Built Environment, Queen's University Belfast, Queen's Marine Laboratory, 12-13 The Strand, 6 Portaferry, Northern Ireland, UK

7 2. Marine Scotland Science, Scottish Government, Marine Laboratory, Aberdeen, Scotland, UK

8 3. School of Chemistry and Chemical Engineering, Queen's University Belfast, Queen's Marine Laboratory, $12-13$ The Strand, Portaferry, Northern Ireland, UK

4. Scottish Association for Marine Science (SAMS), University of the Highlands and Islands, Oban, Argyll, Scotland, UK

5. School of Biological Sciences, Queen's University Belfast, Chlorine Gardens, Belfast, Northern Ireland, UK

*Corresponding author: nhorne01@qub.ac.uk

\section{Abstract}

The marine renewable energy industry is expanding as countries strive to reach climate targets as set out in the Paris Agreement. For tidal energy devices, the potential risk for animals to collide with a device, particularly its moving parts such as rotor blades, is often a major barrier in the consenting process. Theoretical work surrounding collision risk has commonly made use of a formulaic modelling approach. However, whilst providing a platform to assess conventional horizontal axis tidal turbines, the frameworks applied lack the flexibility to incorporate novel device designs or more complex animal movement parameters (e.g. dive trajectories). To demonstrate the novel simulation-based approach to estimating collision probabilities a hypothetical case study was used to demonstrated how the approach can assess the influence that variations in ecological and behavioural data had on collision probabilities. To do this, a tidal kite moving in a 3D figure-of-eight trajectory and a seal-shaped object were modelled and variations to angle of approach, speed and size of the animal were made. To further improve the collision risk estimates, results of the simulations were post-processed by integrating a hypothetical dive profile. The simulations showed how variation in the input parameters and additional post-processing influence collision probabilities. Our results demonstrate the potential for using this simulation-based approach for assessing collision risk, highlighting the flexibility it offers by way of incorporating empirical data or expert elicitation to better inform the modelling process. This framework, where device type, 
configuration and animal-related parameters can be varied with relative simplicity, on a case-by-case basis, provides a more tailored tool for assessing a diverse range of interactions between marine renewable energy developments and receptors. In providing a robust and transparent quantitative approach to addressing collision risk this flexible approach can better inform the decision-making process and aid progress with respect to developing a renewable energy industry in a sustainable manner. Therefore, the approach outlined has clear applications that are relevant to many stakeholders and can contribute to our ability to ensure we achieve sustainable growth in the marine renewable energy industry as part of a global strategy to combat climate change.

Keywords: Collision-risk, simulations, marine mammal, tidal energy, environmental impact assessment 
The marine renewable energy industry is expanding as countries strive to reach climate targets as set out in the Paris Agreement (McCollum et al., 2018), whilst also aiming to achieve the Sustainable Development Goals, as outlined by the United Nations (United Nations, 2015). In regions with sufficiently rapid and energetic tidal flows, such as in waters around the UK, US and Canada, tidal energy offers a predictable renewable energy source (Zhou et al., 2017). In many countries, the construction of any major marine infrastructure project requires the potential ecological impacts to be quantified and, where deemed necessary, monitored. Approved mitigation plans also need to be in place, prior to the regulator providing consent for the development (Moura et al., 2010). Sites identified for tidal energy devices (TEDs) tend to be relatively close to shore and, as one would expect, in tidally dynamic and energetic environments. These areas are often important to a wide range of protected species (Benjamins et al., 2015; Copping et al., 2016). Therefore, any potential impacts to protected populations following the construction and/or operation of proposed developments must be considered as part of an environmental impact assessment (EIA) (Moura et al., 2010). In progressing the tidal energy industry, one of the barriers to consent is the risk of animal collisions with TED(s) (Wilson et al., 2006). However, given the logistical challenge of gathering animal behaviour data close to TEDs, a modelling approach is often adopted, and the assessment typically follows the precautionary principle. Consequently, the construction of large-scale arrays of TEDs remains in the planning stage, in part due to the increased perceived risk to protected species through potential impacts, namely collision risk.

Collision risk models (CRMs) estimate the impact of collisions to a relevant population or management unit for the receptor of concern. A number of models exist to estimate collision risk; including the commonly used Band model (Band, 2000; Band et al., 2016) and encounter rate model (ERM) (Wilson et al., 2006), with two more recent examples, one proposed by Copping and Grear (2018) and another, using an agent-based approach, by Rossington and Benson (2020). All these models use a geometric model of the rotor, as well as animal shape and movement to calculate a theoretical risk of collision. These models were designed for horizontal axis turbines (HAT), however other device designs have, and are, being developed, including cross-flow turbines (ORPC, n.d.), floating turbines (Orbital Marine, n.d.) and tidal kites (Zambrano, 2016); the motion and shape of these devices differ to HATs (Horne et al., 2019). Consequently, the geometric nature of these models means that they are not capable of estimating collision risk for these novel TEDs, which can often have more complex movement patterns, particularly in the case of a tidal kite (Fig. 1) (Booth et al., 2015; Schmitt et al., 2017). 
98 A simulation-based approach was developed to estimate the collision risk for tidal kites using computer-aided-design software, FreeCAD (FreeCAD., 2017), built on previous collision risk approaches by incorporating the simulation of the three-dimensional (3D) figure-of-eight movement of the TED (Schmitt et al., 2017). Schmitt et al (2017) used a uniform distribution of an approaching object (based on the basic morphology of a swimming seal) over many simulations to calculate a collision probability with the TED and tether. Further development of this simulation-based approach has been made using Blender (Blender, 2018), an open-source game-engine software, to demonstrate how collision risk can be assessed, with ease, for a variety of TED designs including a crossflow turbine (Horne et al., 2019). Blender offers advantages over FreeCAD, such as an integrated collision detection system, and the ability to incorporate additional parameters of interest, such as changing the angle of approach.

The current suite of collision risk models is limited with respect to the user's ability to incorporate the best available information and scientific evidence into the model framework, in order to provide a robust estimate of collision risk, and the associated uncertainties. A robust estimate would increase confidence in assessments and better assist regulators in making informed decisions regarding the consenting of marine renewable energy projects. For example, previously used collision risk models are unable to alter ecological inputs, such as angle of approach, where the Band model assumes an animal adopts a single horizontal approach to the device (Scottish Natural Heritage, 2016) and the ERM assumes an equal probability of approach from any angle (Wilson et al., 2006). In reality, the angle of approach may differ for different receptors of interest (Wilson et al., 2006). In addition, the equations used in these models assume linear relationships between ecological inputs (such as size and speed of animals) with the risk of collision, which is unlikely to accurately represent the true complexity of the situation. Lastly, these models have a limited capacity for incorporating additional spatio-temporal empirical data, such as the dive profiles of animals. The simulation-based approach can help overcome such problems by allowing the user to alter input parameters such as the animal size, speed and angle of approach. Moreover, it is possible to include additional behavioural data, such as dive profiles, during post-processing, to further refine collision risk estimates.

The objective of this paper is to demonstrate how variations in input parameters (animal size, speed, angle of approach) can be incorporated into the simulation-based approach with relative ease. Furthermore, we outline the method for post-processing results from the simulations to incorporate 
additional information on animal behaviour (dive profile). For this, we apply hypothetical scenarios using a seal-shaped object and a tidal kite address the following questions: 1) How does varying the animal speed, size and angle of approach affect collision risk probabilities and 2) how does the incorporation of a dive profile further refine collision risk probabilities. By addressing these questions, we provide a worked example of how the simulation-based approach can allow for a comprehensive assessment of collision risk, which is often required for assessing the potential ecological impacts of tidal energy projects.

Figure 1. Tidal kite schematic showing a wing and tether (light grey) undertaking a 3-D figure-of-eight movement (black dashes). The dark grey ellipsoid represents a seal-shaped object moving towards the tidal kite. Note: The co-ordinate system uses $\mathrm{XYZ}$ axis; where $\mathrm{X}$ is the direction of the tidal flow, $\mathrm{Y}$ is the horizontal distance normal to the flow direction and $Z$ represents the distance from the seabed.

\section{Methods}

\subsection{Model Development}

The simulated tidal kite was produced from a 3D shapefile of the device, previously described in Horne et al (2019). The shapefile was a representation of the Minesto kite with a tether length of $20 \mathrm{~m}$ and a wingspan of $3 \mathrm{~m}$. The movement of the kite was simulated in Blender (version 2.79b) using three angles of rotation around the base of the device to create a figure-of-eight motion. The formulas used to calculate these angles are described in Schmitt et al (2017) and were transcribed into a python script for use in Blender; this code essentially controlled the movement of the kite during simulations. To ensure the reliability of results and that there were no issues with the recoding, results for identical scenarios were compared between Blender and the original model in FreeCAD, which showed a satisfactory margin of error of $<1 \%$. 


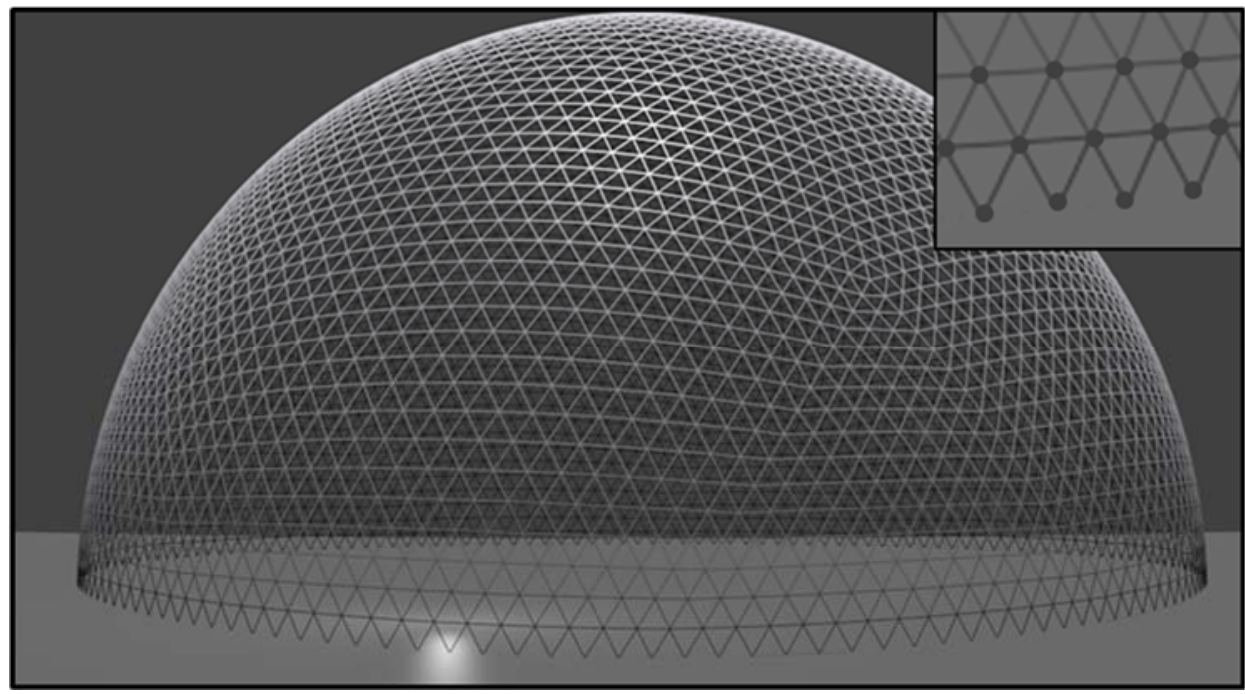

Figure 2: An example of an icosphere created in Blender with the upper right panel showing a close-up of the starting positions (dots) of the seal-shaped objects.

Previous simulations were run for a seal-shaped object moving horizontally and parallel to the flow direction (Horne et al., 2019; Schmitt et al., 2017). However, the investigation of arbitrary directions of travel posed a problem, since starting positions must be assigned in such a way that all directions of animal movement are considered. To address this, starting positions were distributed on the surface of an icosphere, with a radius larger than the kite's swept area and centred on the base of the kite's tether. An icosphere, made up of equilateral triangles, was used to create a dome of possible starting positions of the animal (Fig. 2). The positions where the lines of the triangles met, were used as the starting positions for seal-shaped object approaches during simulations (Fig. 2). The number of starting positions were determined by the number of subdivisions used to create the dome. The more subdivisions, the more complex (higher resolution) the sphere, where a single subdivision results in a sphere with 12 starting positions, two subdivisions create 42 positions, and so on. The number of subdivisions and the radius of the sphere combined determine the distance between each starting position. After creating the sphere, all points from one half were removed to create a dome so that starting positions could originate from no lower than the seabed. For the scenarios tested here, the radius of the icosphere was $21 \mathrm{~m}$ with six subdivisions, which resulted in 5,106 starting positions with $0.9 \mathrm{~m}$ distance between each neighbouring position. 
The values for the ecological parameters, speed, size and angle of approach, were chosen to represent feasible scenarios in the way a seal could hypothetically approach a turbine. The speed of the animal was set using a value for linear velocity and was defined before every simulation. Two different speeds were tested, one, representing the mean swim speed of an adult harbour seal (Phoca vitulina) (1.8 ms ${ }^{-1}$; Scottish Natural Heritage, 2016) which is referred to as the 'slow' speed (Table 1). A second speed of $4 \mathrm{~ms}^{-1}$ was chosen to represent a seal travelling in a fast flowing tidal stream, such as that of the Narrows tidal channel in Strangford Lough, Northern Ireland, UK (Kregting and Elsäßer, 2014) or the Bay of Fundy, Canada (Durand et al., 2008).

An ellipsoid object was used to represent the shape of a harbour seal and the dimensions used in the simulations were representative of an adult seal ( $L=1.41 \mathrm{~m}, \mathrm{~W}=0.3 \mathrm{~m}$ ) (Scottish Natural Heritage, 2016) and a pup ( $L=0.8 \mathrm{~m}, \mathrm{~W}=0.2 \mathrm{~m}$ ) (Cottrell et al., 2002). To change between the two, the length (L) and width (W) of the seal-shaped object was altered before each run, where required. Two manipulations to the dimensions of the shapefile were used to display the flexibility of the system, however any animal shape or size could be incorporated as a 3D shapefile.

The angle of approach for each seal-shaped object was created using yaw and pitch parameters which were input before each simulation (Fig. 3). Yaw is the orientation in the X-Y plane, clockwise relative to the flow direction (Fig. 1), whereas pitch is the orientation in the vertical plane of motion, relative to horizontal. For the scenarios tested herein, the orientation of the seal is the same as the direction of travel i.e. the seal-shaped objects travelled headfirst however, if required, any orientation can be incorporated with ease. Two different inputs for angle of approach were tested, one where the seal travelled downstream toward the device, parallel to the seabed (Fig. 3A), referred to as the 'flat' trajectory (Table 1) and the other where the seal travelled downstream toward the device with a $45^{\circ}$ downward trajectory (Fig. 3B) referred to as the 'downward' trajectory (Table 1).

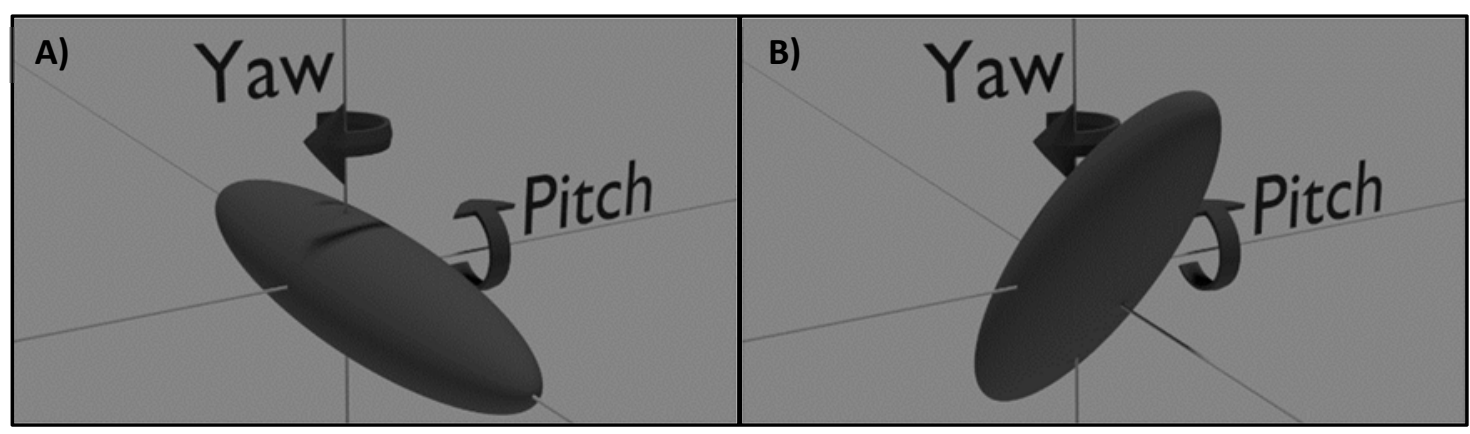

Figure 3: The yaw $(Y)$ and pitch $(P)$ of the seal-shaped objects for the baseline case $(Y=0, P=0)(A)$ and alternative case $(Y=0$, $\mathrm{P}=45)(\mathrm{B})$. 
Simulations were run on a Dell OptiPlex 7060 with an Intel Core i5-8500 and 16GB RAM using the step-by-step conceptual outline in Figure 4. The device shapefile was imported into Blender and the python script controlling device movement was then configured. The animal shape file was then imported, and the starting position of the animal set. Eight different scenarios were tested (Table 1) and collisions were deemed to occur if the seal-shaped object collided with any part of the tidal kite (e.g. wing and/or tether; Fig. 1). These scenarios were set up using three combinations of the input parameters: swim speed, size and angle of approach.

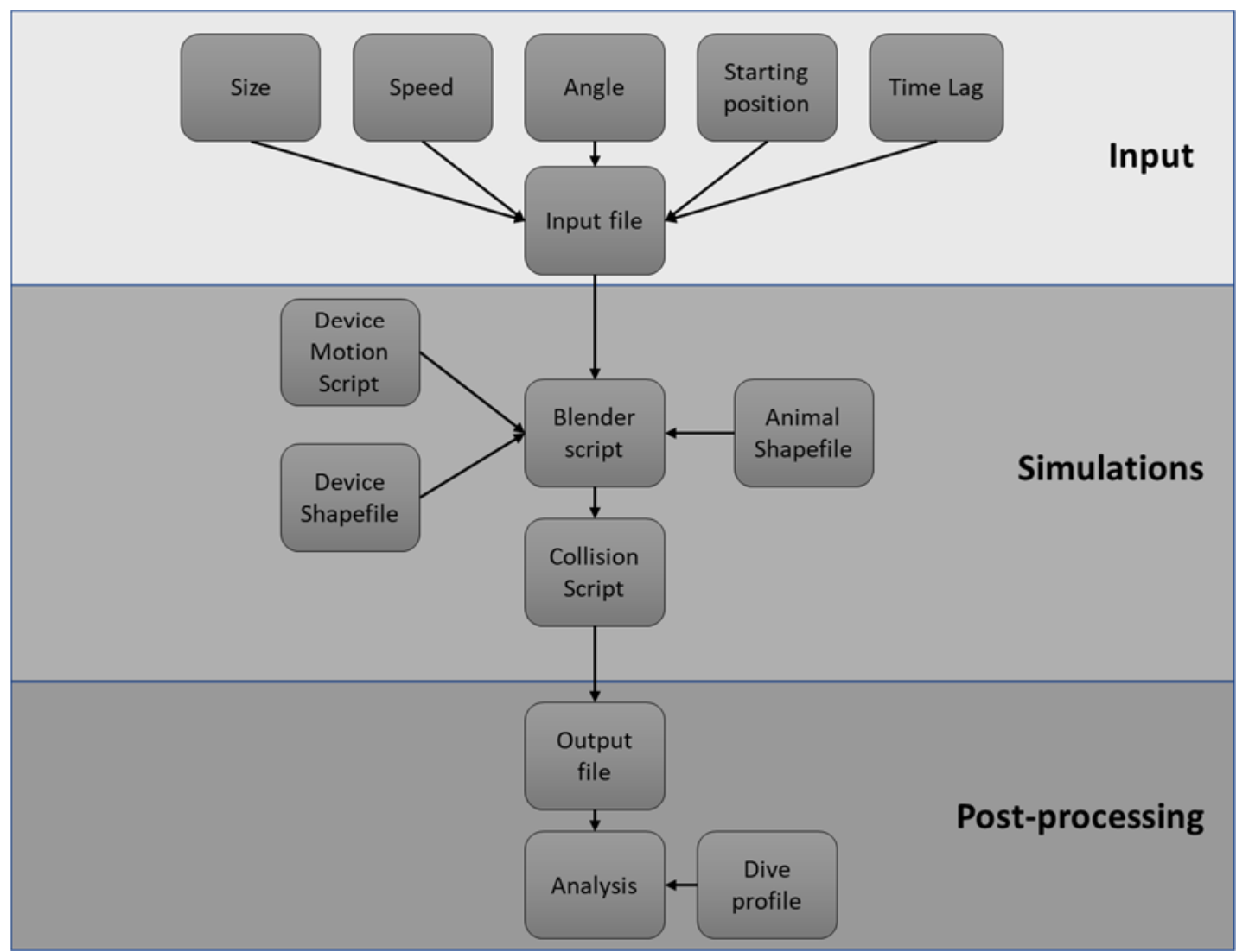

Figure 4: The key processes used in the simulation-based approach, outlining the three discrete steps: creating the input parameters and associated files, running the simulations, and the post-processing step (if additional empirical data are available to further refine collision risk estimates).

Whether the animal collided with the kite or passed unhindered depended on both the relative timing of the animal and the device movement in the simulations. Therefore, to evaluate collision probabilities, animals that were released from the same starting position, were varied at time lags distributed evenly between $0 \mathrm{~s}$ and $8 \mathrm{~s}$ (the time taken for one complete figure-of-eight movement of the kite). Resolution of this lag had to be sufficient to capture the true probability of a collision, which was defined as the number of collisions at a position divided by the overall number of seal- 
shaped objects released from that position (i.e. number of lags). The required resolution could not be established a priori and had to be determined by performing convergence studies. For this, it was logical to assume that larger and slower animals would run a higher risk of collision than smaller, faster ones. Therefore, smaller and faster moving animals would need a greater number of lags to resolve the fewer instances of collisions. Consequently, the fast $\left(4 \mathrm{~ms}^{-1}\right)$ and small (pup) seal-shaped object on a downward trajectory was used to perform the convergence study.

The reliability of the simulations were tested using the method outlined in Eça \& Hoekstra (2014), which is used in numerical modelling to assess the convergence behaviour of simulations and the grid size required for simulations to be accurate. Following this method, an R score of less than 1 indicates that convergence had been achieved; in this case, convergence was achieved at 100 lags $(R=0.495)$. Therefore, the scenarios used herein were run with 100 lags (which equated to a gap of $0.08 \mathrm{~s}$ between each time lag). Consequently, for each of the eight scenarios tested, 510,600 individual simulations were required (i.e. 5,106 starting positions with 100 lags per position).

\subsection{Analysis}

All data processing, error checking and analysis was performed in R (R Core Team., 2019). Outputs from each scenario were matched to the corresponding input file, which created a database for each simulation run. Firstly, the number of collisions at an individual starting position were divided by the number of time lags $(n=100)$ to create a collision probability for each starting position (Table 1 ).

As simulations were run using a dome of starting positions to allow a wide range of scenarios to be tested, the positions of collisions must be translated from 3D to 2D positions for an average collision probability to be calculated. This was achieved by removing the axis in alignment with the direction of travel (i.e. the direction of tidal flow; X-axis (Fig. 1) to project the results in the YZ plane (Fig. 5)). To translate the downward trajectory scenarios into $2 \mathrm{D}$, the positions had to be rotated so that they aligned with at least one axis. The axis chosen was the same axis that the flat $\left(0^{\circ}\right)$ scenarios were run in to allow for a direct comparison. Therefore, new positions were calculated by rotating the 3D vectors by the trajectory $\left(45^{\circ}\right)$ to align them with the flat $\left(0^{\circ}\right)$ scenarios. After this conversion, positions no longer maintained equal distances between points (Fig. 5B); to account for this, inverse distance weighting (IDW) (Pebesma, 2004), which uses the distance between each point to average the values over 2D space, was used. The overall collision probability was then calculated, using the 2D vectors and the collision probability for each individual position. 

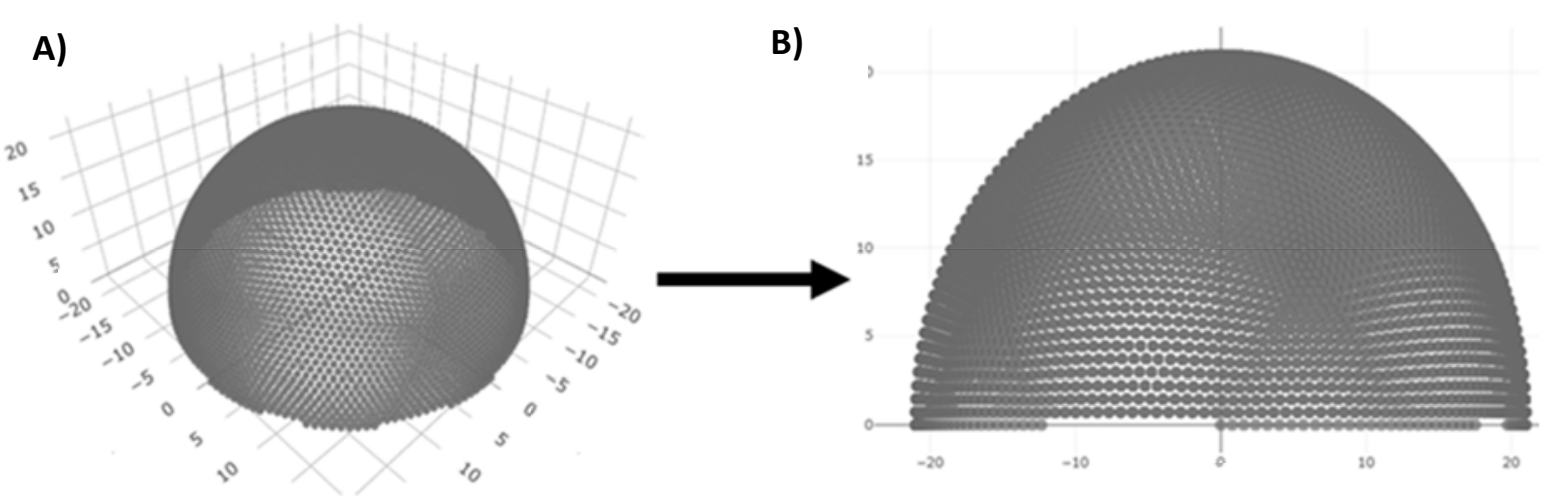

263

264

265

266

267

268

269

270

271

272

Figure 5: The transformation from 3D A) to 2D B) starting positions. Note that at the edges of the 2D plot the points are closer together (higher density).

\subsection{Dive profiles}

The influence of a hypothetical dive profile on the probability of collision was investigated during post-processing. For this, a 'U-shaped' dive profile was used, based on data presented by Thompson et al (2016) for a telemetry tagged adult harbour seal. A time-depth distribution, at $1 \mathrm{~m}$ intervals throughout the water column along the z-axis, was incorporated as a post-processing step, using R. Therefore, rather than assuming an unrealistic uniform distribution throughout the water column ( $z$ axis; Fig. 5), incorporating information on the dive profile (i.e. the proportion of time spent at a given depth throughout the water column) can provide improved estimates of collision risk. Both the hypothetical and the uniform (equal probability for each $1 \mathrm{~m}$ interval) dive profiles were tested for a single scenario: a slow-moving, flat trajectory, adult seal. Updated collision risk probabilities were calculated by multiplying the collision probability for each starting position by the probability for that depth interval. After applying the dive profiles, the IDW methods outlined above were used to calculate the overall collision probability.

\section{Results}

\subsection{Ecological Inputs}

Varying the ecological inputs (i.e. the size of animal, speed and angle of approach) did change the collision probabilities (CP), with the highest chance of collision occurring for a slow $\left(1.8 \mathrm{~ms}^{-1}\right)$ downward trajectory adult $(C P=0.214)$ (Table 1$)$, as compared to a fast $\left(4 \mathrm{~ms}^{-1}\right)$ pup on a downward trajectory, which had the lowest collision probability $(C P=0.037)$ (Table 1$)$. 
Table 1: Results of the different input scenarios. The three-letter code in the scenario column refers to the ecological inputs used: the first letter represents the approach speed; $4 \mathrm{~ms}^{-1}\left(\mathbf{F}\right.$; fast) or $1.8 \mathrm{~ms}^{-1}(\mathbf{S}$; slow).,the second letter refers to the angle of approach; with a flat (F) or downward (D) trajectory, while the third letter refers to the size of the seal; adult (A) or pup (P). Positions are the number of starting positions in which at least one collision occurs. Collisions are the total number of collisions across those positions and $\mathbf{C P}$ is the collision probability calculated using inverse distance weighting.

\begin{tabular}{|l|r|r|r|r|r|l|}
\hline Scenario & \multicolumn{1}{|c|}{ Speed } & \multicolumn{1}{c|}{ Angle } & \multicolumn{1}{c|}{ Size } & Positions & \multicolumn{1}{c|}{ Collisions } & \multicolumn{1}{c|}{ CP } \\
\hline FFP & $4 \mathrm{~ms}^{-1}$ & Flat & Pup & 174 & 875 & 0.0583 \\
\hline SFA & $1.8 \mathrm{~ms}^{-1}$ & Flat & Adult & 224 & 4,477 & 0.2004 \\
\hline FFA & $4 \mathrm{~ms}^{-1}$ & Flat & Adult & 224 & 2,501 & 0.1155 \\
\hline SFP & $1.8 \mathrm{~ms}^{-1}$ & Flat & Pup & 177 & 1,520 & 0.0898 \\
\hline FDP & $4 \mathrm{~ms}^{-1}$ & Down & Pup & 317 & 1,117 & 0.0371 \\
\hline SDA & $1.8 \mathrm{~ms}^{-1}$ & Down & Adult & 353 & 7,587 & 0.2140 \\
\hline FDA & $4 \mathrm{~ms}^{-1}$ & Down & Adult & 353 & 4,435 & 0.1293 \\
\hline SDP & $1.8 \mathrm{~ms}^{-1}$ & Down & Pup & 333 & 2,176 & 0.1293 \\
\hline
\end{tabular}
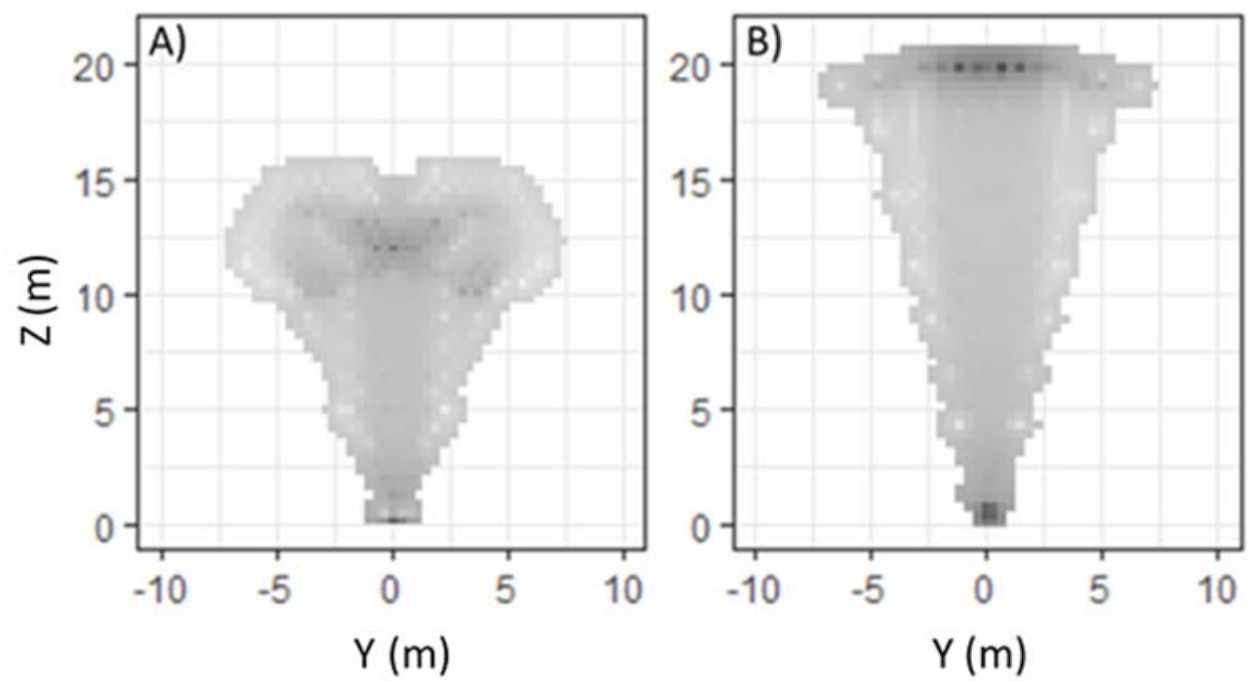

Figure 6: The 2D distribution of the probability of collisions for two of the eight scenarios tested A) Slow, Flat, Adult (SFA) and B) Slow, Downward, Adult, (SDA). The other four scenarios are presented in the supplementary material (supplementary material, Fig. 1). The shading of the points relates to the probability of collision for that point (with darker shading indicating a higher probability of collision).

Across all scenarios, the highest collision probabilities occurred the static base of the device (Fig. 6; supplementary material, Fig. 1). There was a larger distribution of collisions over the z-dimension for the downward trajectory scenario (Fig. 6B), as compared to the flat trajectory scenario (Fig. 6A), whereby approximately $5 \mathrm{~m}$ is added on the z-axis (Fig. 6B). The increase in the possible area for collisions is due to the movement of the tidal kite, whereby, at the largest 2D projected swept area, 
304

305

306

307

308

309

310

311

312

313

314

315

316

317

318

319

320

321

322

323

324

325

326

327

328

329

it operates at approximately $45^{\circ}$, meaning that the device will be perpendicular to the $45^{\circ}$ trajectory of the animal (resulting in an increase in the available surface area for collisions).

Small changes can be seen when comparing across speed of movement or size of an animal. For example, a slow-moving adult on a flat trajectory (SFA) $(C P=0.2004$; Table 1) showed a higher CP throughout the swept area, as compared to a fast-moving pup on a flat trajectory (FFP) (CP = 0.0898; Table 1). More broadly, and as expected, a faster animal had an overall lower CP (Table 1), where the mean CP was $0.086(s d=0.044)$ and $0.150(s d=0.059)$ for scenarios incorporating fast and slow seals, respectively. Similarly, larger seals, on average, were more likely to collide with the kite, as compared to their smaller counterparts. In this case, the mean CP for an adult and a pup was 0.165 $(s d=0.050)$ and $0.079(s d=0.040)$, respectively. However, when comparing CPs for flat trajectories against $45^{\circ}$ downward trajectories, results were not as definitive. While three of the four downward trajectory scenarios showed a higher $\mathrm{CP}$, as compared to the flat trajectory equivalents (i.e. the same speed and size), in the case of the fast and downward moving pup (FDP), a lower collision probability was observed $(C P=0.0371$; Table 1$)$ as compared to the flat trajectory $(C P=0.0583$; Table 1).
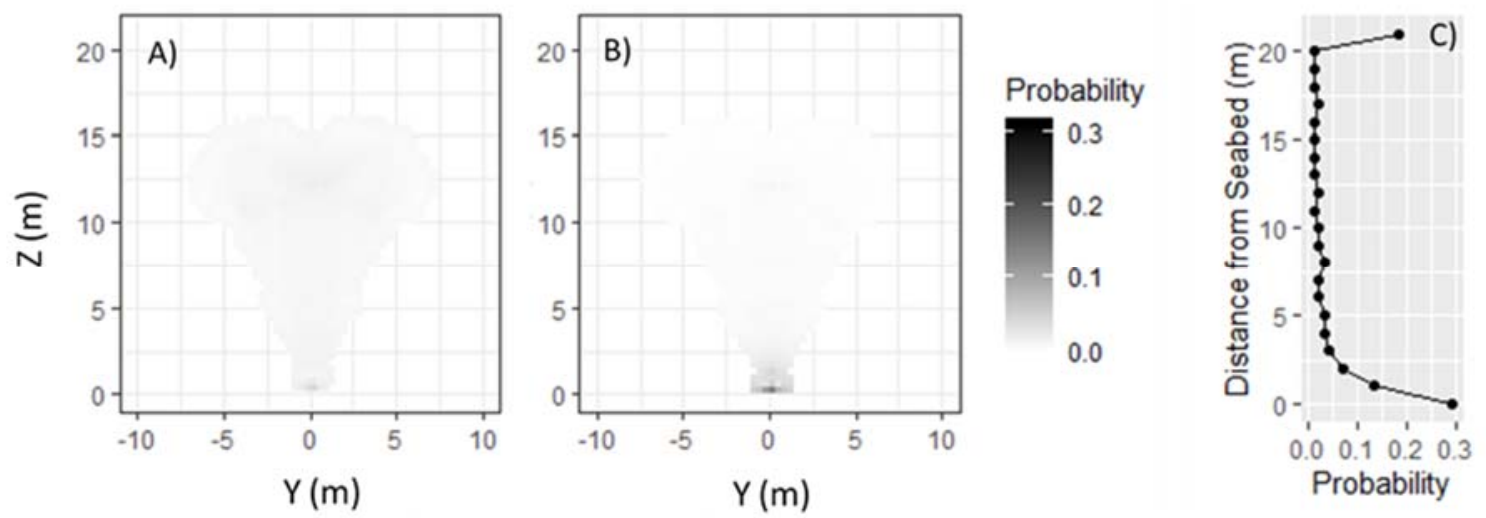

Figure 7: 2D distribution of collision probabilities with the shading showing the probability of collision for each location (with darker colours indicating a higher probability of collision). A) the probability distribution for a uniform time depth profile $\mathbf{B}$ ) the probability distribution when the hypothetical dive profile presented in $\mathbf{C}$ ) is employed in post-processing.

\subsection{Dive profiles}

The collision scenarios represent only a single transit probability without any information on the animal's distribution throughout the water column. By incorporating a uniform dive profile, giving an animal an equal chance of being at any depth, the CP for a slow moving, flat trajectory adult is reduced from 0.214 (Table 1) to 0.009 . By incorporating a hypothetical dive profile to this scenario, the $\mathrm{CP}$ is reduced further, to 0.007 . Figure 7 displays the distribution of collisions for the uniform time depth distribution (Fig. 7A) and when the hypothetical dive profile is included (Fig. 7B) during 
post-processing. Comparison of the two distributions highlighted that the majority of collisions where the dive profile has been employed occur near the base of the device, which is intuitive, given that the base was static and this was the location within the water column where the animal has the highest probability of occurrence (Fig. 7C).

\section{Discussion}

This flexible, simulation-based approach to collision risk assessment allows the incorporation of device specifications and information on the ecology and behaviour of the receptor(s) of interest. These input parameters can be changed with ease when more empirical data become available, for example, or if the user wants to assess thresholds or the potential impact of variations in the I input parameters, as demonstrated herein. Consequently, the simulation-based approach can be used to provide more detailed, transparent and robust collision risk probabilities, and can therefore contribute to our ability to ensure we achieve sustainable growth in the marine renewable energy industry as part of a global strategy to combat climate change.

The approach has potential advantages over other collision risk models, such as the ERM and Band model, which use only a horizontal approach (equivalent to the flat trajectory tested herein) and a uniform distribution of trajectories (Scottish Natural Heritage., 2016). As demonstrated here, CPs can be affected considerably by the angle of approach, where the $45^{\circ}$ downward trajectory scenarios showed a larger distribution of collisions, due to the movement characteristics of the tidal kite. Efforts to incorporate varying angles of approach for wind turbines and birds have been made using mathematical equations similar to those in the ERM and Band model (Holmstrom et al., 2011). However, this approach has not been used when assessing TEDs, and it is similarly limited in its ability to estimate collision risk with novel turbine designs. Given the development of different TED designs, such as HATs (Simec Atlantis Energy., n.d.) and cross-flow turbines (ORPC., n.d.), investigations into the angle of approach are likely to be important if we are to better understand the risk that different TED designs pose to receptors of interest.

Another benefit of the simulation-based approach is that relationships between input parameters can be investigated. Herein, to provide a basic example of this, three input parameters; animal speed, size and angle of approach, were explored. In comparison, both the ERM and the Band model use simplified relationships with changes to inputs, where the equations used to calculate probabilities assume a linear relationship between impact probability and changes to speed or animal length. These assumptions may not be correct, as different parameters relative to the receptor of interest (e.g. shape, speed or angle of approach) and device characteristics (e.g. device type) could alter the relationship between these covariates. Therefore, the dynamic nature of the 
simulation-based approach means these relationships can be explicitly assessed and this can be done with a wide range of parameters for any device design (Horne et al., 2019).

The ability to incorporate empirical data into collision risk estimates is a valuable attribute of this simulation-based approach. However, there are a growing number of studies showing that sitespecific variations in the environment and associated animal behaviour are characteristic within these high energy environments (Hastie et al., 2016; Joy et al., 2018; Lieber et al., 2018; Russell, 2016). Therefore, when applying this approach to a real-world scenario, it is likely that site-specific data, where available, would generate more robust and accurate estimates of collision risk. However, where few empirical data exist, as so often is the case, then the simulation-based approach can be used to assess worst case scenarios. Within the thresholds of what are considered plausible, this would be true for both the receptor and the TED (e.g. if a developer wanted to assess the potential ecological impacts at the design phase).

Key behavioural considerations for understanding collision risk are avoidance (an animal avoiding the area of a device; 'far-field') and evasion (an animal evading being struck by the moving part of the device; 'near-field') (Wilson et al., 2006). In the case of marine mammals and TEDs, there is a lack of empirical data on these behaviours, as such, assessments may opt to use the worst case scenario (where there is no avoidance or evasion) or, a range of avoidance rates, e.g. $10,20,50 \%$ of animals will avoid collisions (Scottish Natural Heritage, 2016). However, recent studies have shown that harbour seals changed their behaviour as a result of the SeaGen device, the first grid-connected operational TED (Joy et al., 2018; Sparling et al., 2018). In this case, Sparling et al (2018) found that, during operation there was no barrier-effect caused by the device, however, there was a reduction in movement of GPS tagged seals passing the TED during operation. Joy et al (2018), also using the GPS tag data from these seals, investigated the direction and speed of movement of the animals. Incorporating these data within the ERM, Joy et al (2018) estimated a 90\% reduction in collision risk. As well as understanding behavioural changes around TEDs, observing fine-scale underwater movement in close proximity (e.g. $<50 \mathrm{~m}$ ) would improve our understanding of collision risk (Wilson et al., 2006). Developments to quantify and better understand underwater movement of animals in these tidally energetic environments is being addressed through three different technologies; active acoustic monitoring (Hastie et al., 2019; Lieber et al., 2014; Williamson et al., 2017), passive acoustic monitoring (Gillespie et al., 2020; Macaulay et al., 2017; Malinka et al., 2018) and through animalborne loggers (Gabaldon et al., 2019; McKnight et al., 2019). These methods provide information on how animals move in three-dimensional space, which will provide valuable empirical data, such as angle of approach, animal speed, dive profile, and avoidance and evasion behaviours, that can be used to better inform this simulation-based approach to collision risk models. 
The simulation-based approach was developed to build on previous CRMs that have been employed to predict the risk to animals posed by tidal energy devices. However, the principles that underpin the simulation-based approach can be employed, with ease, to a wide range of systems and scenarios that predict wildlife collision risk such as wind turbines with birds and bats (Masden and Cook, 2016) or ship strikes with whales (Williams and O'Hara, 2010). Therefore, the application of this simulation-based approach to provide a quantitative assessment on which to address other management and conservation questions is extensive.

\subsection{Conclusion}

This proof-of-concept study demonstrates the feasibility of simulation-based approaches to quantifying collision risk probabilities that can incorporate the best available scientific evidence and, where lacking, expert elicitation, to provide robust and transparent outputs that can consider uncertainties (i.e. variations in the input parameters). The development of this approach is ongoing, aligned with the overall aim of creating a user-friendly and flexible collision risk assessment tool. The intention is to produce an end product that will be useful to developers and consultants when it comes to undertaking collision risk modelling for environmental assessments, and for informing regulators and their advisors when considering the potential impacts on receptors during the application phase of a development.

\section{Acknowledgements}

The Bryden Centre project is supported by the European Union's INTERREG VA Programme, managed by the Special EU Programmes Body (SEUPB). The views and opinions expressed in this paper do not necessarily reflect those of the European Commission or the Special EU Programmes Body (SEUPB).

\section{References}

Band, B., 2000. Windfarms and birds: Calculating a theoretical collision risk assuming no avoiding action, Guidance Note Series, Scottish Natural Heritage.

Band, B., Sparling, C., Thompson, D., Onoufriou, J., Martin, E.S., West, N., 2016. Refining estimates of collision risk for harbour seals and tidal turbines, Scottish Marine and Freshwater Science. https://doi.org/10.7489/1786-1

Benjamins, S., Dale, A.C., Hastie, G., Waggitt, J.J., Lea, M.A., Scott, B., Wilson, B., 2015. Confusion reigns? A review of marine megafauna interactions with tidal-stream environments. Oceanogr. Mar. Biol. An Annu. Rev. 53, 1-54. https://doi.org/10.1201/b18733 
Blender, O.C., 2018. Blender - a 3D modelling and rendering package.

Booth, C., Sparling, C., Wood, J., Tollitt, D., Scott-Heyward, L., Rexstad, E., Hultgren, Y., Johnsson, M., Knutzen, E., 2015. Advancing a key consenting risk for tidal energy: The risk of marine mammal collision for in-stream tidal energy, in: Proceedings of the 3rd Marine Energy Technology Symposium METS2015 April 27-29, 2015, Washington, D.C. p. 4.

Copping, A.E., Grear, M.E., 2018. Applying a simple model for estimating the likelihood of collision of marine mammals with tidal turbines. Int. Mar. Energy J. 1, 27-33. https://doi.org/10.36688/imej.1.27-33

Copping, A.E., Sather, N.K., Hanna, L., Whiting, J., Zydlewski, G.B., Staines, G., Gill, G., Hutchison, I., O’Hagan, A.M., Simas, T., Bald, J., Sparling, C., Wood, J., Madsen, E., 2016. Annex IV 2016 State of the Science Report: Environmental effects of marine renewable energy development around the world. https://doi.org/10.1097/JNN.0b013e3182829024

Durand, N., Cornett, A., Bourban, S., 2008. 3D Modelling and Assessment of Tidal Current Energy Resources in the Bay of Fundy, in: 3rd International Conference on Ocean Energy, 6 October, Bilbao. pp. 2-7.

Eça, L., Hoekstra, M., 2014. A procedure for the estimation of the numerical uncertainty of CFD calculations based on grid refinement studies. J. Comput. Phys. 262, 104-130. https://doi.org/10.1016/j.jcp.2014.01.006

Gabaldon, J., Turner, E.L., Johnson-Roberson, M., Barton, K., Johnson, M., Anderson, E.J., Alex Shorter, K., 2019. Integration, Calibration, and Experimental Verification of a Speed Sensor for Swimming Animals. IEEE Sens. J. 19, 3616-3625. https://doi.org/10.1109/JSEN.2019.2895806

Gillespie, D., Palmer, L., Macaulay, J., Sparling, C., Hastie, G., 2020. Passive acoustic methods for tracking the 3D movements of small cetaceans around marine structures. PLoS One 15 (5). https://doi.org/https://doi.org/10.1371/journal.pone.0229058

Hastie, G.D., Bivins, M., Coram, A., Gordon, J., Jepp, P., MacAulay, J., Sparling, C., Gillespie, D., 2019. Three-dimensional movements of harbour seals in a tidally energetic channel: Application of a novel sonar tracking system. Aquat. Conserv. Mar. Freshw. Ecosyst. 29, 564-575. https://doi.org/10.1002/aqc.3017

Hastie, G.D., Russell, D.J.F., Benjamins, S., Moss, S., Wilson, B., Thompson, D., 2016. Dynamic habitat corridors for marine predators; intensive use of a coastal channel by harbour seals is modulated by tidal currents. Behav. Ecol. Sociobiol. 70, 2161-2174. 
461

462

463

464

465

466

467

468

469

470

Holmstrom, L., Hamer, T., Colclazier, E., Denis, N., Verschuyl, J., Ruché, D., 2011. Assessing avianwind turbine collision risk: An approach angle dependent model. Wind Eng. 35, 289-312. https://doi.org/10.1260/0309-524X.35.3.289

Horne, N., Culloch, R., Schmitt, P., Kregting, L., 2019. Incorporating different tidal energy device designs into 4D collision risk simulations allowing increased flexibility for industry. Proc. 13th Eur. Wave Tidal Energy Conf. 12-13.

Joy, R., Wood, J.D., Sparling, C.E., Tollit, D.J., Copping, A.E., McConnell, B.J., 2018. Empirical measures of harbor seal behavior and avoidance of an operational tidal turbine. Mar. Pollut. Bull. 136, 92-106. https://doi.org/10.1016/j.marpolbul.2018.08.052

Kregting, L., Elsäßer, B., 2014. A hydrodynamic modelling framework for strangford lough part 1: Tidal model. J. Mar. Sci. Eng. 2, 46-65. https://doi.org/10.3390/jmse2010046

Lieber, L., Nimmo-Smith, W.A.M., Waggitt, J.J., Kregting, L., 2018. Fine-scale hydrodynamic metrics underlying predator occupancy patterns in tidal stream environments. Ecol. Indic. 94, 397-408. https://doi.org/10.1016/j.ecolind.2018.06.071

Lieber, L., Williamson, B., Jones, C.S., Noble, L.R., Brierley, A., Miller, P., Scott, B.E., 2014. Introducing Novel Uses of Multibeam Sonar To Study Basking Sharks in the Light of Marine Renewable Energy Extraction 2-4.

Macaulay, J., Gordon, J., Gillespie, D., Malinka, C., Northridge, S., 2017. Passive acoustic methods for fine-scale tracking of harbour porpoises in tidal rapids. J. Acoust. Soc. Am. 141, 1120-1132. https://doi.org/10.1121/1.4976077

Malinka, C.E., Gillespie, D.M., Macaulay, J.D.J., Joy, R., Sparling, C.E., 2018. First in situ passive acoustic monitoring for marine mammals during operation of a tidal turbine in Ramsey Sound, Wales. Mar. Ecol. Prog. Ser. 590, 247-266. https://doi.org/10.3354/meps12467

Marine, O., n.d. Orbital Marine [WWW Document]. URL https://orbitalmarine.com/

Masden, E.A., Cook, A.S.C.P., 2016. Avian collision risk models for wind energy impact assessments. Environ. Impact Assess. Rev. 56, 43-49. https://doi.org/10.1016/j.eiar.2015.09.001

McCollum, D.L., Zhou, W., Bertram, C., De Boer, H.S., Bosetti, V., Busch, S., Després, J., Drouet, L., Emmerling, J., Fay, M., Fricko, O., Fujimori, S., Gidden, M., Harmsen, M., Huppmann, D., Iyer, G., Krey, V., Kriegler, E., Nicolas, C., Pachauri, S., Parkinson, S., Poblete-Cazenave, M., Rafaj, P., 
Rao, N., Rozenberg, J., Schmitz, A., Schoepp, W., Van Vuuren, D., Riahi, K., 2018. Energy investment needs for fulfilling the Paris Agreement and achieving the Sustainable Development Goals. Nat. Energy 3, 589-599. https://doi.org/10.1038/s41560-018-0179-z

McKnight, J.C., Bennett, K.A., Bronkhorst, M., Russell, D.J.F., Balfour, S., Milne, R., Bivins, M., Moss, S.E.W., Colier, W., Hall, A.J., Thompson, D., 2019. Shining new light on mammalian diving physiology using wearable near-infrared spectroscopy. PLoS Biol. 17, 1-20. https://doi.org/10.1371/journal.pbio.3000306

Moura, A., Simas, T., Batty, R., Wilson, B., Thompson, D., Lonergan, M., Norris, J., Finn, M., Veron, G., Paillard, M., Abonnel, C., 2010. Scientific guidelines on Environmental Assessment : Equitable Testing and Evaluation of Marine Energy Extraction Devices in terms of Performance, Cost and Environmental Impact.

Nations, U., 2015. Transforming our world: The 2030 Agenda for Sustainable Development, Draft resolution referred to the United Nations summit for the adoption of the post-2015 development agenda by the General Assembly at its sixty-ninth session. UN Doc. A/70/L.1. https://doi.org/10.1201/b20466-7

ORPC, n.d. ORPC [WWW Document]. URL https://www.orpc.co/our-solutions/scalable-gridintegrated-systems/tidgen-power-system

Pebesma, E.J., 2004. Multivariable geostatistics in S: The gstat package. Comput. Geosci. 30, 683691. https://doi.org/10.1016/j.cageo.2004.03.012

Rossington, K., Benson, T., 2020. An agent-based model to predict fish collisions with tidal stream turbines. Renew. Energy 151, 1220-1229. https://doi.org/10.1016/j.renene.2019.11.127

Russell, D.J.F., 2016. Activity Budgets : Analysis of seal behaviour at sea (OESEA-15-66) Report for the Department of Business, Energy and Industrial Strategy.

Schmitt, P., Culloch, R., Lieber, L., Molander, S., Hammar, L., Kregting, L., 2017. A tool for simulating collision probabilities of animals with marine renewable energy devices. PLoS One 12. https://doi.org/10.1371/journal.pone.0188780

Scottish Natural Heritage, 2016. Assessing collision risk between underwater turbines and marine wildlife, SNH guidance note.

Sparling, C., Lonergan, M., McConnell, B., 2018. Harbour seals (Phoca vitulina) around an operational tidal turbine in Strangford Narrows: No barrier effect but small changes in transit behaviour. Aquat. Conserv. Mar. Freshw. Ecosyst. 28, 194-204. https://doi.org/10.1002/aqc.2790 


\section{Supplementary Materials}
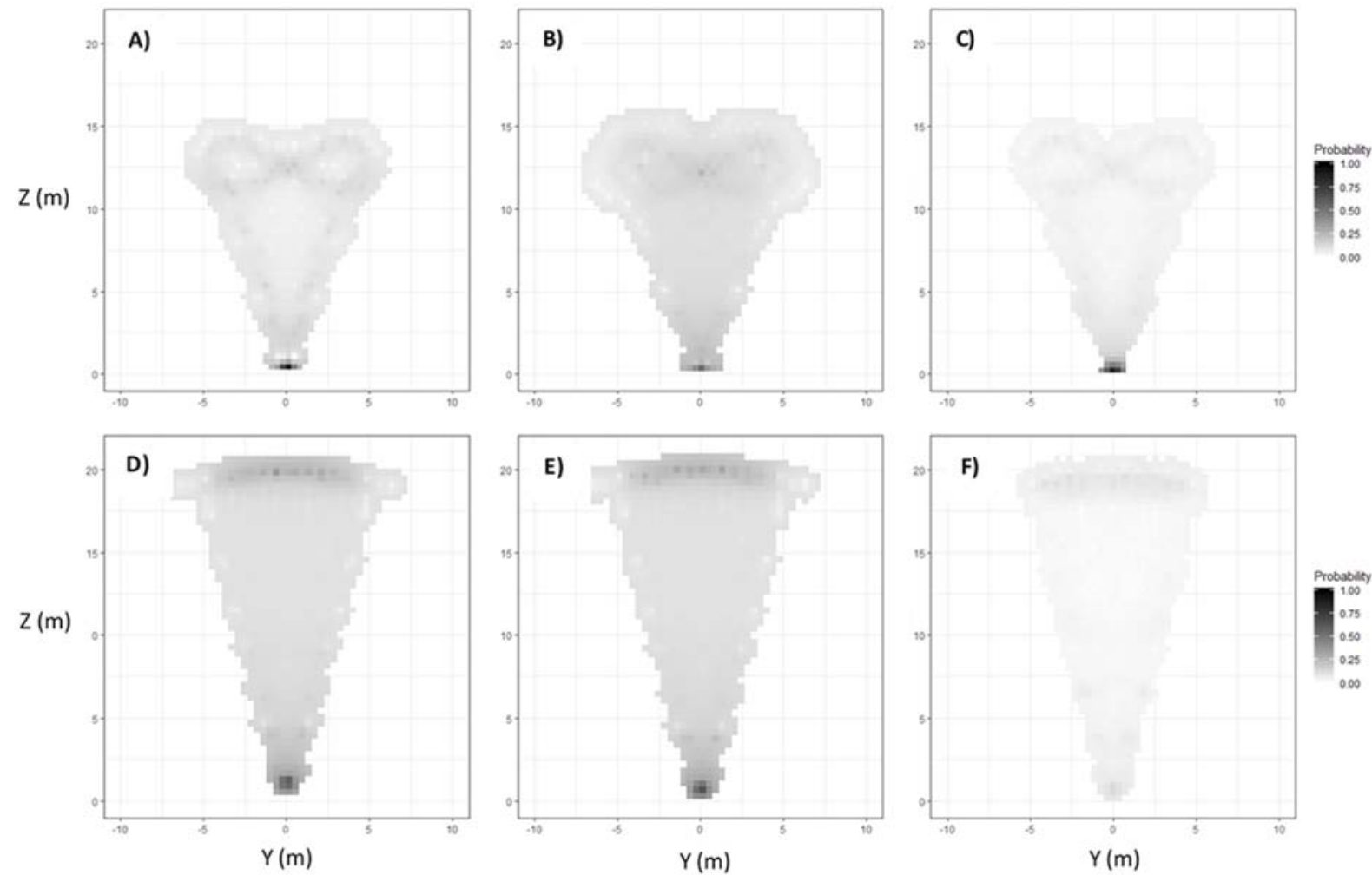

Figure 1: The 2D distribution of the probability of collisions for two of the eight scenarios tested A) Slow, Flat, Pup (SFP); B) 

indicating higher probability of collision). 